San Jose State University

SJSU ScholarWorks

Faculty Publications

Social Work

January 2004

\title{
Strain experienced by caregivers of dementia patients receiving palliative care: Findings from the Palliative Excellence in Alzheimer's Care Efforts (PEACE) program
}

\author{
Sadhna Diwan \\ San Jose State University, sadhna.diwan@sjsu.edu \\ Gavin W. Hougham \\ University of Chicago \\ Greg A. Sachs \\ University of Chicago
}

Follow this and additional works at: https://scholarworks.sjsu.edu/social_work_pub

Part of the Social Work Commons

\section{Recommended Citation}

Sadhna Diwan, Gavin W. Hougham, and Greg A. Sachs. "Strain experienced by caregivers of dementia patients receiving palliative care: Findings from the Palliative Excellence in Alzheimer's Care Efforts (PEACE) program" Journal of Palliative Medicine (2004): 797-807. https://doi.org/10.1089/ jpm.2004.7.797

This Article is brought to you for free and open access by the Social Work at SJSU ScholarWorks. It has been accepted for inclusion in Faculty Publications by an authorized administrator of SJSU ScholarWorks. For more information, please contact scholarworks@sjsu.edu. 


\title{
Strain Experienced by Caregivers of Dementia Patients Receiving Palliative Care: Findings from the Palliative Excellence in Alzheimer Care Efforts (PEACE) Program
}

\author{
SADHNA DIWAN, Ph.D., ${ }^{1}$ GAVIN W. HOUGHAM, Ph.D. ${ }^{2}$ and GREG A. SACHS, M.D. ${ }^{2}$
}

\begin{abstract}
Background: Programs that provide palliative care to individuals with dementia, which is a progressive terminal illness, are likely to encounter different issues (e.g., management of problem behaviors, caregiver strain extending over years) from those typically addressed by hospice programs. Little research is available on palliative care for individuals with dementia who live in the community.

Objective: This study examines predictors of types of strain experienced by caregivers of community-dwelling patients with dementia enrolled in a unique demonstration program titled Palliative Excellence in Alzheimer Care Efforts (PEACE), which moved palliative care "upstream," integrating palliative care into the primary care of patients with dementia.

Design: Data were collected through structured, face-to-face interviews with 150 community-dwelling, predominantly African American patient-caregiver dyads who were enrolled in the PEACE program.

Measurements: Established measures, including the Caregiver Strain Index, the Revised Memory and Behavior Problems Checklist, and the Katz Index of Activities of Daily Living, were used in addition to other measures assessing caregiver, patient, and situational characteristics.

Results: Factor analysis of the Caregiver Strain Index revealed three dimensions of strain (role, personal, and emotional) related to caregiving. Using a stress process model, regression analyses examined stressors and resources related to patient, caregiver, and support system characteristics in predicting these three dimensions of strain among caregivers. Patient problem behaviors predicted all types of caregiver strain. Perceived lack of support from the health care team predicted personal and emotional strain, whereas higher income, surprisingly, predicted role strain. Patient functional limitations predicted personal and role strain.

Conclusions: Findings suggest that effective palliative care programs for patients with dementia need to understand and address the various sources and types of caregiver strain; provide adequate support to caregivers for the management of problem behaviors; provide counseling to help cope with the emotional reactions to the cognitive and behavioral changes associated with dementia progression; facilitate communication with the health care team; and broker access to community and other resources for assistance with functional limitations. Further research examining changes in strain over time will provide useful insights on the delivery of care and services for patients with dementia and their families in a palliative care framework.
\end{abstract}

\footnotetext{
${ }^{1}$ Center for Health Administration Studies, School of Social Service Administration, University of Chicago, Chicago, Illinois.

2Section of Geriatrics, Department of Medicine, University of Chicago, Chicago, Illinois.
} 


\section{INTRODUCTION}

$\mathbf{T}$ WO IMPORTANT TRENDS in end-of-life care in recent years have been increasing efforts to improve care for patients dying from conditions other than cancer, and attempts to move palliative care "upstream" from hospice referral. These trends have the most to offer people dying with Alzheimer's disease and other dementias for two reasons. First, dementia is a progressive terminal illness ${ }^{1}$ that is rapidly becoming one of the most common conditions affecting older people. The number of older persons with Alzheimer's disease and other dementias is projected to increase from approximately 4 million today to approximately 14 million by the year $2050 .^{2}$ Second, although guidelines for referring patients with dementia to hospice have been created, only $7 \%$ of patients in hospice care have a diagnosis of dementia. ${ }^{3}$ Among the many barriers to hospice care for dementia patients is Medicare's requiring a prognosis of survival of 6 months or less to qualify for the hospice benefit. Even patients with severe dementia needing an institutional level of care can remain in that advanced stage for several years, ${ }^{4}$ leaving the majority of dementia patients without access to hospice care. ${ }^{5}$

There is a growing recognition of the need to move palliative care farther upstream in the course of dementia-well before typical referrals to hospice are made-because several studies are showing that satisfactory palliation of symptoms leads to improved comfort and quality of life. ${ }^{6}$ Examples of innovative programs attempting to provide excellent end-of-life care for patients with dementia are quite recent both in community-dwelling 7,8 and institutional settings. ${ }^{9}$ As palliative care programs move upstream, however, they are increasingly likely to encounter clinical conditions and issues that differ from what most providers typically see in hospice care. For example, a palliative care program for patients with dementia will not only need to address the management of symptoms associated with dementia but also address their impact on caregivers. A recent study by Schulz et al., ${ }^{10}$ found end-of-life care for patients with dementia to be extremely demanding of family caregivers. Caregivers exhibited high levels of depressive symptoms while providing care to the relative with dementia, and more than $50 \%$ of the caregivers reported feeling "on duty" 24 hours per day, had ended or reduced employment because of care- giving, and that the patient had frequent pain. Thus, as advocated by Sachs ${ }^{11}$ the interface between geriatrics, palliative medicine, and gerontology is particularly important to the development of appropriate and effective models of palliative care.

In this study we examine the nature of strain experienced by caregivers of patients with dementia who were enrolled in the Palliative Excellence in Alzheimer Care Efforts (PEACE) program at the University of Chicago. The PEACE program is a hybrid model that attempts to bridge the gap between palliative care and dementia care by combining care management strategies that attempt to address the full range of needs of dementia patients and their caregivers. Two key aspects of existing research on caregiving are particularly germane to our study of a model to provide better end-of-life care to patients with dementia. First, unlike research on the family survivors of hospice patients that has focused on anticipatory grief and bereavement over weeks or months, for patients with dementia the caregiving "career" of a family member usually spans several years. This requires a very different orientation to care management than what may be typical for hospice programs. Second, we concur with Haley et al., 12 that the use of theoretical models to understand the nature of caregiving in this population is particularly useful in facilitating research "that can guide conceptually and empirically based psychosocial intervention." Thus, we adopted the Stress Process Model $^{13}$ to explore the nature and predictors of caregiver strain in our sample of dementia patients receiving palliative care. This model has been widely used in the gerontological literature to understand strain among caregivers of dementia patients, and most recently was applied to understanding the experience of spousal caregivers of hospice patients. ${ }^{12}$

The stress process model consists of three core components: stressors, resources, and outcomes. Stressors refer to the hardships that challenge the adaptive capacities of people; social and personal resources refer to internal and external factors that people can mobilize to contain, regulate, or ameliorate the effect of stressors; and outcomes refer to the effect of stressors after the impact of available resources are taken into account. Stress not only arises from traumatic events resulting from disasters or diseases, but also from one's position in the social structure. Thus, inequalities in 
social status, financial and other resources, education, or race, for example, can affect both the exposure to stressors and the personal and social resources available to differentially adapt to or ameliorate such stressors. ${ }^{13}$

Both the gerontological and the palliative care literatures point to stressors and resources relevant to addressing the unique needs of dementia patients and their caregivers, and to the outcomes of caregiving stress. Outcomes of stress typically examined in the literature include caregiver depression, decreased life satisfaction, health problems, ${ }^{14}$ and appraisal of emotional distress or adverse impact in various spheres such as work, family, and personal life as a result of providing care. ${ }^{15,16}$ The impact of caregiving varies by the nature of the illness and the relationship of the caregiver. For example, compared to caring for individuals who do not have dementia, caregivers of dementia patients experience greater emotional strain-especially because of changes in cognition, mood, and behavior of the patient with dementia. ${ }^{16}$ Despite providing fewer hours of actual care, adult children sometimes report more caregiving burden than do spouses, ${ }^{17}$ a paradox that might be explained by the fact that children may experience greater role strain or conflict because of competing demands on their time, and that spouses may discount some activities as routine and expected household tasks (e.g., preparing meals, housekeeping, managing finances), rather than reporting them as "caregiving" activities. ${ }^{16}$ Within the stress process framework, stressors are seen to arise from patient and caregiver characteristics, while support system characteristics are resources that influence the amount of strain experienced by the caregiver. Stressors faced by caregivers of hospice patients include role fatigue, lack of support and information, poor coordination of services, and increased distress associated with greater intensity of patient symptoms such as pain, nausea, and loss of appetite. ${ }^{18}$ Resources that could ameliorate the experience of strain include formal and informal caregiving support, caregiver appraisals, and coping responses. ${ }^{19}$ The two most significant resources in end-of-life care associated with improved quality of life for patients and their families are the palliation of pain and other symptoms, ${ }^{20}$ and the provision of support to families by the health care team (physician, nurse, and others), which includes accessibility, continuity of care, consistency in team communication and coordination, and appropriate referral to hospice. $^{21}$

In this paper, we examine the types of strain experienced by caregivers of dementia patients enrolled in the PEACE program. Using the stress process framework we drew from both the gerontological and palliative care literatures to help us understand the stressors, resources, and strain associate with end-of-life caregiving to patients with dementia. Caregiver strain in this study is construed as the perceived negative impact of caregiving on various aspects of the caregiver's life assessed through the Caregiver Strain Index. ${ }^{22}$ Based on a review of the literature and our clinical experiences with PEACE participants, we examined the following questions: (1) Are there distinct dimensions to the strain experienced by caregivers of dementia patients receiving palliative care? (2) What are the common and distinctive factors associated with the different types of strain experienced by caregivers? A better understanding of the nature and predictors of caregiver strain will help provide useful information to service providers in terms of designing and delivering effective palliative care services for dementia patients, and adjuvant support services to their families.

\section{METHODS}

\section{Setting/sample}

The PEACE program at the University of Chicago was funded as part of The Robert Wood Johnson Foundation's "Promoting Excellence in End-of-Life Care Initiative." The goals of PEACE were to develop, implement, and evaluate an innovative model for providing palliative care to patients with dementia and their families. As described in more detail by Shega et al., ${ }^{7}$ the PEACE program is a disease management model for dementia. The focus of PEACE is on advance care planning and goal setting consistent with the stage of disease, proactive symptom elicitation and management, multidisciplinary patient and family education on disease processes, extensive caregiver support, optimal utilization of community resources, and improved coordination of care between primary and specialty care physicians. The PEACE program was coordinated through the primary care outpatient geriatrics practice of the Section of Geriatrics at the Uni- 
versity of Chicago. A total of 150 patient-caregiver dyads were recruited sequentially (with more than $90 \%$ agreeing to participate) from the Windermere Senior Health Center (WSHC), which provides primary care to approximately 2200 older adults in a comprehensive, multidisciplinary fashion. The average age of patients at this clinic is 80 , two thirds of the patients are women, and approximately two thirds are African American. The clinic provides primary care to approximately 500 patients with dementia. None of these patients are enrolled in Medicare health management organizations (HMOs) or other capitated systems, making coordination of care across different providers and sites a labor-intensive challenge.

The staff involved with the PEACE study included nine geriatric fellowship-trained physicians, one social worker, and two clinical nurse specialists. Patients and caregivers of patients enrolled in PEACE were interviewed separately, with each interview taking between 15 and 40 minutes to complete. Verbal consent was obtained from the patient and the proxy, or if the patient lacked decision-making capacity as measured by a brief screening tool, proxy consent and patient assent sufficed. A variety of other services (psychiatry, nutrition counseling, occupational and physical therapy) were available on site for immediate referral if necessary. After the research interviews were completed, PEACE nurses reviewed the interviews over the following days and made follow-up telephone calls and referrals to help resolve manifest problems. Common issues addressed included additional conversations and recommendations about: nutrition support for patients experiencing dysphagia; appropriate medication regimens; multiple strategies for managing behavioral problems; and discussions about referrals to hospice, home health agencies, adult daycare, respite, and homemaker services. The data presented here are from the initial interviews of enrollees in PEACE. All procedures of the PEACE study, including the use of verbal consent, were reviewed and approved by the Institutional Review Board (IRB) of the University of Chicago Medical Center.

\section{Measures}

Outcome measures consisted of three dimensions of caregiver strain that were constructed through a factor analytic procedure from the 13- item Caregiver Strain Index (CSI) ${ }^{22}$ which has been widely used in the health care literature.

Patient characteristics were assessed by caregiver report. Patient functioning in cognitive, affective, and behavioral domains were assessed by the three subscales of the Revised Memory and Behavioral Problem Checklist (RMBPC). ${ }^{23}$ The reliability $(\alpha)$ coefficients were 0.83 for the cognition scale, 0.82 for the depression subscale, and 0.79 for the behavior subscale. Patient's functional limitations were assessed using the Katz Index of Activities of Daily Living (ADLs) ${ }^{24}$ and a scale assessing instrumental ADLs. ${ }^{25}$ Patient pain was assessed by caregiver reports, describing the pain experienced by the patient on an average day using a verbal descriptor scale (VDS). The VDS ascertains the presence and severity of pain on a 7 -point scale $(0=$ no pain to $6=$ pain as bad as it can be), and the scale's psychometric properties in persons with and without cognitive impairment have been well described in the literature. ${ }^{26}$

Caregiver characteristics were assessed by the following: Race was self-identified by the respondent and coded as $1=$ Caucasian, $2=$ African American, and $3=$ Other (included Hispanic and Asian); Annual income was measured as an ordinal variable with the following response categories: $\$ 5000$ or less, $\$ 5000-9,999$, and then $\$ 10,000$ to $\$ 60,000$ in $\$ 10,000$ increments, with the final category being $\$ 60,000$ or over; and Relationship was coded as $1=$ spouse or spouse equivalent, $2=$ adult child, and $0=$ other (included daughters-in-law and other caregivers). Some might argue that daughters-in-law and sons-in-law should be considered in the same category as children, however, in this sample, there were only two daughters-in-law and no sons-inlaw who were identified as the patient's primary caregiver. Results of regression analyses that included daughters-in-law as adult children did not differ from the analyses presented here.

Support system characteristics were assessed by the following: Formal service referral to one or more of the following resources: information and educational materials, support groups, community resources and services, and respite care. A higher score on this summative scale (0-4) indicates more referrals. Caregiver's perception of support received from the health care team was a dichotomous variable with a response of yes/no; and availability of informal support was measured by a dichotomous variable (yes/no) 
that asked whether there were other informal caregivers providing any care to the patient.

Analysis

Exploratory factor analysis was conducted to determine the dimensionality of the Caregiver Strain Index, and reliability of the subscales was assessed through Cronbach $\alpha$. Ordinary least squares regression was used to examine the predictors of various dimensions of caregiver strain.
All data were analyzed using SPSS 11.0.1 (SPSS Inc., Chicago, IL). ${ }^{27}$

\section{RESULTS}

Table 1 presents the characteristics of the sample (patients and caregivers) enrolled in the PEACE program. Mean age of the patients was 82 years (standard deviation $[S D]=6.8$ ), $75 \%$

Table 1. Demographics of Community-Dwelling Persons with Dementia and their FAMILY CAREgIVERS (dyad $n=150$ )

\begin{tabular}{|c|c|c|c|}
\hline \multicolumn{2}{|l|}{ Patients $^{\mathrm{a}}$} & \multicolumn{2}{|c|}{ Caregivers $^{\mathrm{a}}$} \\
\hline Age (mean $\pm \mathrm{SD})$ & $82 \pm 6.8$ & Age $($ mean $\pm \mathrm{SD})$ & $61.9 \pm 13.5$ \\
\hline Females $n(\%)$ & $112(75 \%)$ & Females $n(\%)$ & $116(77 \%)$ \\
\hline Ethnicity & & Ethnicity & \\
\hline African American & $122(82 \%)$ & African American & $119(79 \%)$ \\
\hline White & $25(17 \%)$ & White & $27(18 \%)$ \\
\hline Other & $2(1 \%)$ & Other & $2(1 \%)$ \\
\hline Marital status & & Marital status & \\
\hline Widowed & $89(59 \%)$ & Widowed & $14(9 \%)$ \\
\hline Married & $45(30 \%)$ & Married & $85(57 \%)$ \\
\hline Divorced/separated & $8(5 \%)$ & Divorced/separated & $30(20 \%)$ \\
\hline Never married & $7(4 \%)$ & Never married & $19(13 \%)$ \\
\hline Living status & & Caregiver relation to patient & \\
\hline With relatives (nonspouse) & $70(47 \%)$ & Daughter & $75(50 \%)$ \\
\hline With spouse/spouse equivalent & $31(21 \%)$ & Spouse & $33(22 \%)$ \\
\hline Alone & $25(17 \%)$ & Son & $14(9 \%)$ \\
\hline With spouse and others & $11(7 \%)$ & Other relative & $12(8 \%)$ \\
\hline Group living/facility/non-relatives & $7(4 \%)$ & Friend & $3(2 \%)$ \\
\hline Other/missing & $6(4 \%)$ & Spouse equivalent & $2(1 \%)$ \\
\hline Education & & Daughter-in-law & $2(1 \%)$ \\
\hline Eighth grade or less & $40(27 \%)$ & Other & $9(6 \%)$ \\
\hline High school graduate & $58(39 \%)$ & Annual Household Income & \\
\hline Some college or more & $40(27 \%)$ & Less than $\$ 9,000$ & $8(5 \%)$ \\
\hline Missing & $12(8 \%)$ & $10,000-19,000$ & $20(13 \%)$ \\
\hline & & $20,000-29,000$ & $18(12 \%)$ \\
\hline & & $30,000-39,000$ & $17(11 \%)$ \\
\hline & & $40,000-49,000$ & $11(7 \%)$ \\
\hline & & $50,000-59,000$ & $6(4 \%)$ \\
\hline & & $60,000+$ & $39(26 \%)$ \\
\hline & & Missing & $31(21 \%)$ \\
\hline & & Living with Patient & \\
\hline & & Yes & $92(61 \%)$ \\
\hline
\end{tabular}

aNumbers may not add up to 150 because of rounding or missing data.

$\mathrm{SD}$, standard deviation. 
were female, and $82 \%$ were African American. Fifty-nine percent of the patients were widowed and $30 \%$ were married; $17 \%$ lived alone. Among the caregivers, $77 \%$ were female, $79 \%$ were African American, 50\% were daughters, 22\% were spouses, and $9 \%$ were sons. Sixty-one percent of the caregivers lived with the patient, and $37 \%$ of the caregivers reported an annual income of $\$ 40,000$ or more.

Table 2 presents data on the factor structure of the CSI and reliability of the subscales. Approximately $41 \%$ of the caregivers reported a score on the full CSI of 7 or more, which is the cutoff score used by the scale's originator (Robinson). Similar to Rubio et al., ${ }^{28}$ our initial exploratory factor analysis yielded four factors. However, the fourth factor had an eigenvalue of just 1.0, contributed only $7 \%$ of the overall variance explained, and did not appear to capture an easily understandable domain. Therefore, to be consistent with previous studies ${ }^{28,29}$ using the CSI we constrained the model to produce three factors using the prin- cipal components method with orthogonal (Varimax) rotation. One item labeled "caregiving is inconvenient," loaded roughly equally on all three factors and was dropped in subsequent analyses. The three factors, which are comparable to but not identical with findings reported by others could be construed as assessing (1) adjustment or role strain (work adjustment, family adjustments, change in personal plans, and other demands on time); (2) personal strain (physical strain, financial strain, sleep disturbance, feeling confined, and feeling overwhelmed); and (3) emotional strain (upset because patient has changed, behaviors are upsetting, emotional adjustment). The Kaiser-Meyer-Olkin test of sampling adequacy was 0.77 (a score of 0.60 or higher is desirable), and the three factors cumulatively explained $54 \%$ of the variance in the solution. The reliability of the overall CSI was 0.81 (Cronbach $\alpha$ ), whereas the $\alpha$ for each subscale were: adjustment or role strain $(\alpha=0.72)$, personal strain $(\alpha=0.69)$, and emotional strain $(\alpha=0.61)$.

Table 2. Exploratory Factor Analysis and Reliability of the Caregiver Strain Index

\begin{tabular}{|c|c|c|c|c|}
\hline Variables & $\begin{array}{c}\text { Factor } \\
1\end{array}$ & $\begin{array}{l}\text { Factor } \\
2\end{array}$ & $\begin{array}{c}\text { Factor } \\
3\end{array}$ & $\begin{array}{l}\text { Scale } \\
\alpha\end{array}$ \\
\hline Overall Caregiver Strain Index & & & & 0.81 \\
\hline Adjustment or Role Strain subscale & & & & 0.72 \\
\hline $\begin{array}{l}\text { Family adjustment (Helping has disrupted my routine; there has } \\
\text { been no privacy) }\end{array}$ & 0.81 & & & \\
\hline Work adjustment (I have to take time off for caregiving duties) & 0.69 & & & \\
\hline Other demands on time (Other family members need me) & 0.67 & & & \\
\hline $\begin{array}{l}\text { Personal plan change (I had to turn down a job; I cannot go on } \\
\text { vacation) }\end{array}$ & 0.63 & & & \\
\hline Personal Strain subscale & & & & 0.69 \\
\hline Financial strain (Caregiving is a financial strain) & & 0.75 & & \\
\hline $\begin{array}{l}\text { Overwhelmed (I worry about the person I care for, have concerns } \\
\text { about how I will manage) }\end{array}$ & & 0.65 & & \\
\hline $\begin{array}{l}\text { Physical strain (Lifting in and out of a chair, effort or concentration } \\
\text { is required) }\end{array}$ & & 0.63 & & \\
\hline $\begin{array}{l}\text { Sleep disturbance (The person I care for is in and out of bed or } \\
\text { wanders around at night) }\end{array}$ & & 0.60 & & \\
\hline Confining (Helping restricts free time, or I cannot go visiting) & & 0.53 & & \\
\hline Emotional Strain subscale & & & & 0.61 \\
\hline $\begin{array}{l}\text { Change is upsetting (Person I care for is so much different than } \\
\text { he/she used to be) }\end{array}$ & & & 0.79 & \\
\hline $\begin{array}{l}\text { Behavior is upsetting (Incontinence; the person I cared for has } \\
\text { trouble remembering things) }\end{array}$ & & & 0.77 & \\
\hline Emotional Adjustment (Severe arguments about caregiving) & & & 0.53 & \\
\hline
\end{tabular}


Table 3 contains the results of regression analyses that examine selected predictors of each type of strain. We used pairwise deletion of cases when missing data were encountered to ensure adequate sample sizes for the analyses. The variable with the most missing data was patient pain $(22 \%)$, which resulted from an early interviewer error. Regression analyses with mean value substitution for missing data yielded virtually identical results.

The model predicting adjustment or role strain was statistically significant $(F=4.5 ; d f=12,78$; $p=0.001$ ) and explained $41 \%$ of the variance in the subscale. Increase in problem behaviors and higher caregiver income predicted increased adjustment or role strain. Two variables approaching significance in this model were increased
ADL/Instrumental Activities of Daily Living (IADL) limitations and the absence of informal support.

The model predicting personal strain was significant $(\mathrm{F}=4.5 ; d f=12,78 ; p=0.001)$ and explained $41 \%$ of the subscale variance. Increase in patient problem behaviors, greater ADL/IADL limitations, and perceived lack of support from the health care team predicted increased personal strain.

The model predicting emotional strain was significant $(\mathrm{F}=2.9$; $d f=12,78 ; p=0.002)$ and explained $31 \%$ of the subscale variance. Increased problem behaviors predicted increased emotional strain. Two variables approaching significance in this model were decreased patient cognitive ability and perceived lack of support from the health care team.

Table 3. Regression Analyses: Selected Predictors of Three Subtypes of Caregiver Strain

\begin{tabular}{|c|c|c|c|c|c|c|}
\hline \multirow[b]{3}{*}{ Independent variables } & \multicolumn{6}{|c|}{ Dependent variables } \\
\hline & \multicolumn{2}{|c|}{$\begin{array}{l}\text { Adjustment or role } \\
\text { strain }(\mathrm{n}=150)\end{array}$} & \multicolumn{2}{|c|}{$\begin{array}{l}\text { Personal strain } \\
\quad(\mathrm{n}=150)\end{array}$} & \multicolumn{2}{|c|}{$\begin{array}{l}\text { Emotional strain } \\
\qquad(\mathrm{n}=150)\end{array}$} \\
\hline & Beta & $\mathrm{t}$ & Beta & $\mathrm{t}$ & Beta & $\mathrm{t}$ \\
\hline \multicolumn{7}{|l|}{ Patient characteristics } \\
\hline Behavior & 0.34 & $3.10^{* *}$ & 0.44 & $4.00^{* *}$ & 0.35 & $3.00^{* *}$ \\
\hline Cognition & 0.16 & 1.53 & 0.00 & 0.02 & 0.21 & $1.81^{+}$ \\
\hline Depression & -0.04 & -0.04 & 0.01 & 0.11 & 0.08 & 0.73 \\
\hline Pain on average day & 0.06 & 0.70 & 0.03 & 0.34 & -0.14 & -1.43 \\
\hline $\mathrm{ADL} / \mathrm{IADL}$ & 0.16 & $1.73^{+}$ & 0.31 & $3.27^{* *}$ & 0.08 & 0.82 \\
\hline \multicolumn{7}{|l|}{ Caregiver Characteristics } \\
\hline Spouse & -0.07 & -0.61 & 0.06 & 0.51 & -0.05 & -0.40 \\
\hline Adult child & 0.07 & -0.64 & 0.07 & 0.58 & -0.05 & -0.40 \\
\hline Income & 0.27 & $2.83^{* *}$ & -0.02 & -0.20 & 0.00 & 0.03 \\
\hline Race $(1=$ black, $0=$ other $)$ & 0.02 & 0.29 & 0.04 & 0.46 & -0.09 & -0.90 \\
\hline \multicolumn{7}{|l|}{ Support Characteristics } \\
\hline Formal services & 0.03 & 0.34 & 0.06 & 0.70 & 0.10 & 1.05 \\
\hline HC team support & -0.02 & 0.29 & -0.21 & $-2.30^{*}$ & -0.09 & $1.76^{+}$ \\
\hline Informal support & 0.16 & $1.75^{+}$ & -0.01 & -0.11 & 0.04 & 0.42 \\
\hline \multicolumn{7}{|l|}{ Models } \\
\hline$R^{2}$ & \multicolumn{2}{|c|}{0.41} & \multicolumn{2}{|c|}{0.41} & \multicolumn{2}{|c|}{0.31} \\
\hline$F(d f)$ & \multicolumn{2}{|c|}{$4.5(12,78)$} & \multicolumn{2}{|c|}{$4.5(12,78)$} & \multicolumn{2}{|c|}{$2.9(12,78)$} \\
\hline$p$ value & \multicolumn{2}{|c|}{0.001} & \multicolumn{2}{|c|}{0.001} & \multicolumn{2}{|c|}{0.002} \\
\hline
\end{tabular}

$* p<0.05$.

$* * p<0.01$.

$+p<0.10$.

ADL, Activities of Daily Living; IADL, Instrumental Activities of Daily Living; HC, hospice care 


\section{DISCUSSION}

The findings of this study offer us several insights into the nature of strain experienced by caregivers of dementia patients receiving palliative care in a primary care setting. Before we discuss the findings and their implications, however, it is necessary to highlight the nature of this sample. Approximately $80 \%$ of the patients and caregivers in this study were African American with a wide range of income. The Windermere clinic primarily serves individuals and families from the south side of Chicago, which contains a black middle class enclave where $60 \%$ work in whitecollar jobs and the median family income is above the Chicago median. ${ }^{30}$ The south side also contains very poor neighborhoods and the catchment area of the clinic overlaps all of these neighborhood types. The demographics of the patient population are rather unique in terms of representing the diversity that is seen within the African American population, which is not always true of similar clinics or practices located in other urban areas in the country, which tend to serve mostly Caucasians. Although the sample is representative of those who come to this clinic and the surrounding community, it contrasts sharply with existing data on hospice participants where in 2001, $82 \%$ were white and only $8 \%$ were African American. ${ }^{3}$ Thus, although our sample demographic profile may limit the comparability of the findings to existing studies, the study helps fill an important gap in the literature on strain among African American caregivers of patients with dementia. In addition, many hospices are working to extend services to greater numbers of minority patients and families, and many palliative care programs are looking at providing care upstream from hospice and for patients suffering from diseases other than cancer. Thus, our subjects represent the kinds of patients and families that hospices and palliative care organizations increasingly will be called upon to serve in the coming years. Those qualifications aside, with respect to our two research questions, our findings replicate those of other studies in terms of the multidimensional nature of caregiver strain and the significant burdens imposed by problem behaviors on all aspects of strain.

Using the stress process model to examine the specific predictors of different types of strain helps us better conceptualize and plan potential interventions and services needed to address var- ious aspects of caregiver strain. For example, stressors such as patient problem behaviors were associated with all aspects of caregiver strain, whereas increasing ADL/IADL limitations were associated with greater personal strain, and to a lesser degree with role strain. Thus, services and programs specifically targeted to address these issues may be more likely to provide appropriate relief to caregivers. For example, assistance with ADL/IADL limitations may relieve caregivers from feeling torn between the demands of their many social roles, and may also reduce the actual physical strain of caregiving itself, but specific behavioral management programs (e.g., training and medications), as well as caregiver support through counseling and respite can help caregivers deal with the emotional and personal strain of dealing with the problem behaviors.

In a separate bivariate analysis (data not shown), we found that adult children in this sample were significantly more likely to report role strain compared to spouses and others. These differences, however, did not remain significant in our regression models of the predictors of strain. From what is known in the literature about differences in family structure and function in different populations, this finding warrants additional research into how caregiving burdens differentially affect different kin types. A significant proportion (approximately 60\%) of all caregivers, however, endorsed at least one item of the emotional strain subscale, indicating that it was emotionally difficult for them to cope with the changes in the patient that had occurred as a result of the dementia itself. Thus, palliative care programs need to address not only deterioration of the patient, but also need to help caregivers cope with the loss, stigma, and bereavement issues that arise as patients experience the many cognitive, psychological, and social changes associated with illness progression. ${ }^{31}$

Higher caregiver income was predictive of greater role strain. The findings on the inverse relationship between socioeconomic status (SES) and caregiver strain are consistent with a few other studies, such as Nijboer et al., ${ }^{32}$ who found that higher SES caregivers of patients with cancer derived substantially less self-esteem from caregiving than caregivers of lower SES. With respect to ethnic differences, Pruchno et al., ${ }^{33}$ found that white mothers of adult children with a chronic disability, despite having higher per capita incomes and more education, reported 
greater caregiving burden and less caregiving satisfaction than did African American mothers with less income and education. The inverse relationship between SES and strain in our sample could be interpreted in at least two ways: first, many of these caregivers are still employed, and because the costs of reducing or giving up employment are high, these caregivers juggle between employment and caregiving roles in addition to managing other roles such as spouse or parent. A second potential explanation is that, while our sample is largely urban-dwelling African American, there is a wide income range represented, and higher income individuals are less likely to qualify for free or low-cost community services that might otherwise help these caregivers and thus help reduce the strains associated with managing multiple roles. This is another area in which additional research is needed.

Perceived lack of support from the health care team was associated with greater personal strain, and also appeared to have some influence on emotional strain, which is consistent with findings reported by Grande et al., ${ }^{34}$ who note that caregivers frequently desire more support and reassurance from health care professionals, yet may not often ask for help. This misalignment has great potential to result in many unmet emotional and physical needs for both patients and caregivers. Studies of caregivers of hospice patients suggest that caregivers value getting consistent information from the entire health care team, and continuity of care throughout the end-of-life care period. ${ }^{35}$ Open communication and support from the health care team is particularly valuable as caregivers struggle with patient problem behaviors and with making medical decisions about whether to treat various conditions as they arise. Thus, availability of such support can reduce caregiver strain through supportive, informational, as well as medical interventions for the management of problem behaviors. Open communication and support from the health care team is particularly valuable as caregivers struggle with patient problem behaviors, and with making medical decisions about whether to treat various conditions as they arise. This finding suggests the need to strengthen the roles of the geriatric nurse and social worker in the primary care setting in order to help caregivers manage these patients in the community. A multidisciplinary geriatric team ought to be a valuable resource for supporting the patient and family through in- creased communication, advocacy, and assistance with obtaining needed services. Thus, optimally designed palliative care programs need to be both patient- and caregiver-centered in their approach to care. It should be noted that although existing palliative care and hospice models do address both patient and caregiver concerns, our study demonstrates the need for palliative care teams to focus more specifically on the types of care and services needed to address the needs of caregivers and patients with dementia. Putting our findings together with the work of Schulz and colleagues suggests the need for services may, in fact, be greatest during the extended period of decline before death is imminent.

Contrary to previous findings on the positive relationship between patient pain and caregiver strain, ${ }^{20}$ this association was not significant in our study. Potential reasons for this finding may be that the overall reports of pain in this sample were quite low (mean $=1.7, \mathrm{SD}=1.5$; range, 0 to 6) and thus did not have a great bearing on caregiver strain. It is useful to note that individuals who enrolled in the PEACE program were recruited from patients who were already receiving medical care in a comprehensive geriatric care clinic affiliated with a teaching hospital. The clinicians at this clinic were knowledgeable about and sensitive to pain control issues, and were possibly more likely to address these issues than others in primary care settings. Second, caregivers may be associating patient behavioral manifestations of pain with patient problem behaviors such as agitation, which do have significant associations with different types of caregiver strain. ${ }^{36}$ That we found significant caregiver strain in this population despite low levels of pain is of particular importance for a palliative care audience.

Other resource variables such as formal and informal support were not significantly associated with any type of caregiver strain, which is consistent with the body of caregiving literature that reports largely mixed findings on the relationship between caregiver stress and formal and informal assistance. One explanation for this may have to do with the measurement of formal care. While there were significant positive correlations between referrals to formal services and severity of patient problems with cognition, depression, and behavior, the support variables in this study asked if the caregiver was referred to various services, but did not assess whether the services 
were actually obtained by the caregiver. Similarly, the informal support variable asked if there is a secondary caregiver but did not assess what support, if any, was provided by that caregiver. Thus, the data available in this study may not be completely adequate to assess the role of such resources in reducing the experience of strain.

Using the stress process model to understand predictors of caregiver strain within the palliative care framework highlights the type of stressors, both long- and short-term, that need to be addressed. Delivering palliative care through an outpatient geriatrics practice offers promise in developing models that can effectively address the needs of both patients and caregivers over a longer term than what is typical of hospice programs. Our study demonstrates the need for collaboration between the hospice, palliative care, and Alzheimer's disease care communities to develop effective programs based on models derived from the social sciences that offer meaningful end-of-life support and care to patients with dementia and their families.

\section{ACKNOWLEDGMENTS}

Supported in part by a Robert Wood Johnson Foundation Promoting Excellence in End-of-Life Care grant, Dr. Greg A. Sachs, PI; and by a grant to Dr. Sachs by The Hulda B. and Maurice L. Rothschild Foundation. We wish to thank Ira Byock, Jeanne Twohig, Carol Stocking, Deon Cox Haley, Joseph Shega, Amy Levin, Gina Freed, Katharine Kuball, Tally Moskovitz, Patricia Hanrahan, and Daniel Luchins for their contributions to the PEACE project, and to Sara Leitsch for comments on an earlier draft of this paper.

\section{REFERENCES}

1. Olson E: Dementia and neurodegenerative diseases. In Morrison RS, Meier DE (eds): Geriatric Palliative Care. New York: Oxford University Press, 2003, pp. 160-172.

2. Brookmeyer R, Gray S, Kawas C: Projections of Alzheimer's disease in the United States and the public health impact of delaying disease onset. Am J Public Health 1998;88:1337-1342.

3. National Hospice and Palliative Care Organization. (2003). NHPCO facts and figures. (www.nhpco.org/ files/public/Facts_Figures_Jan_03.pdf (Last accessed on August 7, 2003).
4. Volicer L: Management of severe Alzheimer's disease and end-of-life issues. Clin Geriatr Med 2001;17;377391.

5. Jennings B: Hospice and Alzheimer disease: A study in access and simple justice. Hastings Center Report Special Supplement 2003;33:S24-S26.

6. Lloyd-Williams M, Payne S: Can multidisciplinary guidelines improve the palliation of symptoms in the terminal phase of dementia? Int J Palliat Nurs 2002; 8:370-375.

7. Shega JW, Levin A, Hougham GW, Cox-Hayley D, Luchins D, Hanrahan P, Stocking C, Sachs GA: Palliative Excellence in Alzheimer Care Efforts (PEACE): A program description. J Palliat Med 2003;6:315-321.

8. Volicer L, Hurley AC, Blasi ZV: Characteristics of dementia end-of-life care across care settings. Am J Hosp Palliat Care 2003;20:191-200.

9. Tuch $\mathrm{H}$, Parrish $\mathrm{P}$, Romer AL: Integrating palliative care into nursing homes. J Palliat Med 2003;6:297-309.

10. Schulz R, Mendelsohn, AB, Haley WE, Mahoney D, Allen RS, Zhang S, Thompson L, Belle SH: End-of-life care and the effects of bereavement on family caregivers of persons with dementia. N Engl J Med 2003; 349:1936-1942.

11. Sachs GA: Research at the interface of palliative care and geriatrics. J Palliat Care 2003;19:5-6.

12. Haley WE, LaMonde LA, Han B, Burton AM, Schonwetter R: Predictors of depression and life satisfaction among spousal caregivers in hospice: Application of a stress process model. J Palliat Med 2003;6: 215-224.

13. Pearlin L: Some conceptual perspectives on the origin and prevention of social stress. In: Socioeconomic Conditions, Stress and Mental Disorders: Toward a New Synthesis of Research and Public Policy. National Institute of Mental Health. 1995. (www.mhsip.org/nimhdoc/ socioeconmh_home.htm $\rangle$ (Last accessed June 7, 2003).

14. Haley WE, LaMonde LA, Han B, Narramore S, Schonwetter R: Family caregiving in hospice: Effects on psychological and health functioning among spousal caregivers of hospice patients with lung cancer or dementia. Hosp J 2001;15:1-18.

15. Kramer BJ: Differential predictors of strain and gain among husbands caring for wives with dementia. Gerontologist 1997;37:239-249.

16. Ory M, Yee J, Tennstedt S, Schulz R: The extent and impact of dementia care: Unique challenges experienced by family caregivers. In: Schulz R. (ed): Handbook of Dementia Caregiving: Evidenced-Based Interventions for Family Caregivers, New York: Springer Publishing Company, 2000, pp. 1-32.

17. Schulz R. Quittner A: Caregiving through the life span: An overview and future directions. Health Psychol 1998;17:107-111.

18. Newton M, Bell D, Lambert S, Fearing A: Concerns of hospice caregivers. ABNF Journal 2002;13:140-144.

19. Nijboer $C$, Tempelaar $R$, Triemstra $M$, van den Bos GA, Sanderman R: The role of social and psychologic resources in caregiving of cancer patients. Cancer. 2001;91:1029-1039. 
20. Ferrell BR, Borneman T: Pain and suffering at the end of life for older patients and their families. Generations 1999;23:12-17.

21. Carline JD, Curtis JR, Werich MD, Shannon SE, Ambrozy DM, Ramsey PG: Physician's interactions with health care teams and systems in the care of dying patients: Perspectives of dying patients, family members and health care professionals. J Pain Symptom Manage 2003;25:19-28.

22. Robinson BC: Validation of a Caregiver Strain Index. J Gerontol 1983;38:344-348.

23. Teri L, Truax P, Logsdon R, Uomoto J, Zarit S, Vitaliano PP: Assessment of behavioral problems in dementia: The revised memory and behavior problems checklist. Psychol Aging 1992;7:622-631.

24. Katz S, Ford AB, Moskowitz RW, Jackson BA, Jaffe MW: Studies of illness in the aged. The index of ADL: A standardized measure of biological and psychological function. JAMA 1963;185:914-919.

25. Duke University Center for the Study of Aging and Human Development: Multidimensional Functional Assessment Questionnaire In: Gallo J, Reichel W, Anderson L (eds): Handbook of Geriatric Assessment, 2nd ed. Gaithersburg, MD: Aspen, 1995, pp. 169-170.

26. Herr KA, Mobily PR. Comparison of selected pain assessment tools for use with the elderly. App Nurs Res 1993;6:39-46.

27. SPSS, Inc. SPSS for Windows. Release 11.0.1. Chicago, IL: SPSS Inc., 2001.

28. Rubio DM, Berg-Weger M, Tebb S: Assessing the validity and reliability of well-being and stress in family caregivers. Soc Work Res 1999;23:54-64.

29. Thornton M., Travis S: Analysis of the reliability of the modified Caregiver Strain Index. J Gerontol Soc Sci 2003;58B:S127-S132.

30. Patillo-McCoy M: The limits of out-migration for the black middle class. J Urban Affairs, 2000;22:225-241.
31. Almberg BE, Grafstrom M, Winblad B: Caregivers of relatives with dementia: Experiences encompassing social support and bereavement. Aging Ment Health 2000;4:82-89.

32. Nijboer C, Triemstra M, Tempelaar R, Mulder M, Sanderman R, van den Bos G: Patterns of caregiver experiences among partners of cancer patients. Gerontologist 2000;40:738-746.

33. Pruchno R, Patrick JH, Burant CJ: African American and White mothers of adults with chronic disabilities: Caregiving burden and satisfaction. Family Relations 1997;46:335-347.

34. Grande GE, Todd C J, Barclay S: Support needs in the last year of life: Patient and carer dilemmas. Palliat Med 1997;11:202-208.

35. Carline JD, Curtis JR, Werich MD, Shannon SE, Ambrozy DM, Ramsey PG: Physician's interactions with health care teams and systems in the care of dying patients: Perspectives of dying patients, family members and health care professionals. J Pain Symptom Manage 2003;25:19-28.

36. Buffum M, Miaskowski C, Sands L, Brod M: A pilot study of the relationship between discomfort and agitation in patients with dementia. Geriatr Nurs 2001; 22:80-85.

Address reprint requests to: Sadhna Diwan, Ph.D.

Center for Health Administration Studies School of Social Service Administration

University of Chicago 969 East $60^{\text {th }}$ Street Chicago, IL 60637

E-mail: diwan@uchicago.edu 
Copyright of Journal of Palliative Medicine is the property of Mary Ann Liebert, Inc. and its content may not be copied or emailed to multiple sites or posted to a listserv without the copyright holder's express written permission. However, users may print, download, or email articles for individual use. 